\title{
APLICAÇÃO DE MÉTODO ANALÍTICO PROBABILÍSTICO PARA O PLANEJAMENTO DE RESERVATÓRIOS DE DETENÇÃO
}

\author{
APPLICATION OF PROBABILISTIC ANALYTICAL METHOD FOR PLANNING DETENTION \\ RESERVOIRS
}

\author{
Mauricio Abud GREGÓRIO; Antonio Carlos ZUFFO \\ Faculdade de Engenharia Civil, Arquitetura e Urbanismo - UNICAMP. Avenida Albert Einstein, 901. Campinas - SP \\ E-mails: magud@hotmail.com; zuffo@fec.unicamp.br
}

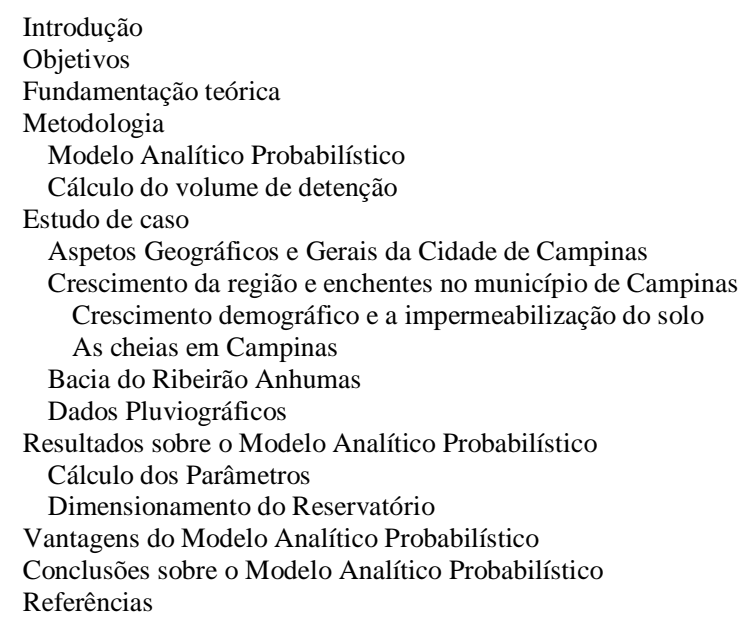

RESUMO - O presente trabalho tem como objetivo apresentar uma metodologia de cálculo rápido para pré-dimensionamento de reservatórios de armazenamento das águas do escoamento pluvial para planejamento da macrodrenagem urbana. O Modelo Analítico Probabilístico, metodologia utilizada, é fundamentado nas distribuições exponenciais de probabilidades do volume total, da duração, da intensidade e dos tempos de inter eventos das chuvas. Partindo-se destas premissas, o cálculo dos parâmetros necessários para sua aplicação é realizado de forma simples e rápida por meio de fórmulas obtidas pelas equações da teoria das probabilidades. Este modelo apresenta um ferramental matemático bem simples, reduzindo o tempo computacional, além de oferecer a possibilidade de simulações expeditas, utilizando os parâmetros hidrológicos da própria região em estudo, necessitando apenas de uma pequena série histórica de dados pluviográficos, sem a necessidade de levantamento das informações flúvio-morfológicas das bacias. Este método seria utilizado na etapa de planejamento urbano e/ou planejamento do sistema de macrodrenagem, pois é um método desenvolvido para um sistema misto de drenagem urbana. A metodologia foi aplicada ao Ribeirão das Anhumas em Campinas, uma bacia urbana bastante urbanizada, cujos resultados foram excelentes. Os volumes assim determinados permitiram determinar os potenciais locais a serem implementados, devido às necessidades mínimas de área e de volumes, sem a necessidade do levantamento de outras informações, que são necessárias para a elaboração de um projeto básico ou executivo.

Palavras-chave: Modelo Analítico Probabilístico. Reservatório de detenção. Escoamento superficial urbano.

\begin{abstract}
The present work has the objective of presenting a rapid calculation methodology for the pre-dimensioning of storage reservoirs of the drainage water for urban macro drainage planning. The Probabilistic Analytical Model, methodology used, is based on the exponential distributions of probabilities of the total volume, duration, intensity and times of rainfall events. Starting from these premises, the calculation of the necessary parameters for its application is carried out in a simple and fast way through formulas obtained by the equations of the probability theory. This model presents a very simple mathematical tool, reducing the computational time, besides offering the possibility of expedited simulations, using the hydrological parameters of the region under study, requiring only a small historical series of rainfall data, without the need of surveying the fluvial-morphological information of the basins. This method would be used in the urban planning and / or planning phase of the macro drainage system, since it is a method developed for a mixed urban drainage system. The methodology was applied to the Anhumas creek in Campinas, a very urbanized urban basin, whose results were excellent. The volumes thus determined made it possible to determine the potential sites to be implemented, due to the minimum area and volume requirements, without the need to collect other information, which is necessary for the preparation of a basic or executive project, used in the urban drainage planning phase.
\end{abstract}

Keywords: Probabilistic Analytical Model. Detention reservoir. Urban surface runoff.

\section{INTRODUÇÃO}

O considerável aumento populacional nas concentrações urbanas seguiu em ritmo intenso nas últimas décadas, com o aumento expressivo do preço do metro quadrado em nossas cidades.
$\mathrm{Na}$ maioria dessas regiões, a ocupação humana ocorreu sem controle, sem planejamento urbano e sem levar em consideração o problema da impermeabilização de grandes áreas. A pressão 
sobre a ocupação do espaço, aliado ao alto preço do metro quadrado urbano, levou a administração pública municipal de Campinas a procurar soluções mais baratas para a instalação de equipamentos urbanos. Campinas sacrificou alguns espaços públicos, geralmente praças, transformando-as em terminais de ônibus urbano, diminuindo-se ainda mais as áreas permeáveis e aumentando a temperatura média no centro da cidade. $\mathrm{O}$ aumento da temperatura urbana leva ao aumento das frequências das chuvas convectivas, que são as responsáveis pelo aumento das ocorrências das cheias urbanas juntamente com a redução da permeabilidade do solo.

O problema das inundações em áreas urbanas na cidade de Campinas intensificou-se entre os anos de 1976 a 2008, diminuindo após 2010, coincidindo com um período mais seco, que levou entre 2014 a 2016, a uma das estiagens mais severas na região Sudeste.

As enchentes urbanas acarretam cada vez mais danos materiais, sociais e humanos, uma vez que as áreas afetadas continuam sendo adensadas. Os prejuízos ligados ao transbordamento dos córregos e rios urbano não trazem apenas perdas materiais, mas principalmente, problemas relacionados à saúde física e mental da população e, não raro, com vítimas fatais.

Uma das soluções para aumentar a eficiência dos sistemas de drenagem das cidades é o aumento da capacidade de condução dos sistemas de macrodrenagem, uma visão higienista.

Porém, esta solução, forçosamente aumenta também a velocidade de escoamento dessas águas, que por sua vez, diminuirão o tempo de concentração dessas bacias, provocando vazões de pico cada vez maiores. O trecho canalizado descarregará esta vazão em pontos mais a jusante, empurrando as enchentes para as periferias ou para áreas fora da área urbanizada. Como as cidades continuam crescendo, este efeito logo será sentido novamente com a expansão dos limites urbanos, pela incorporação das áreas circunvizinhas. Este é um círculo vicioso que se deve evitar, uma abordagem com técnicas compensatórias, que visam minimizar o aumento dos volumes escoados pela retenção de água nos terrenos, ou atraso no escoamento das águas pluviais.

A sobrecarga nos sistemas de drenagem ocorre no momento em que o sistema de drenagem de águas pluviais recebe uma vazão superior à sua capacidade nominal de projeto. Neste momento, pode haver mudança de regime de escoamento em galerias, que deveriam operar em regime livre e passam a operar em carga (escoamento forçado). Galerias operando em carga podem provocar alagamentos quando a carga hidráulica se dê acima da cota do terreno.

$\mathrm{O}$ sistema de macrodrenagem possui um limite hidráulico máximo de esgotamento para cada canal ou galeria construído, quando este limite é atingido ocorrem as enchentes. Este limite é definido como vazão de restrição de uma bacia, ou de trechos de rios. Se atingido esse limite, será necessário avaliar uma solução que integre as várias sub-bacias, bem como em ações de controle e planejamento. Estas ações não são apenas de implantação de obras, mas também de gerenciamento do sistema. Uma das medidas de compensação mais conhecidas pela população brasileira é a construção de reservatórios de detenção, popularmente conhecidos por "piscinões".

$\mathrm{O}$ princípio de funcionamento desses piscinões é o de limitar as vazões de saída a um valor máximo, cuja estrutura hidráulica existente a jusante possa funcionar normalmente. A ideia é segurar e/ou retardar o escoamento da água da chuva na própria bacia, atenuando o pico da cheia, liberando-a de maneira controlada, para diminuir os efeitos nefastos de uma cheia urbana. Os reservatórios de detenção têm esta propriedade de atenuação das ondas de cheias.

A metodologia alternativa para o cálculo do volume do reservatório de detenção (piscinão), aplicado neste trabalho, foi o método estatístico analítico probabilístico, utilizando a teoria da Função de Distribuição de Probabilidade (FDP).

$\mathrm{O}$ método assume que há boa aproximação dos eventos pluviosos, denominados extremos, com uma distribuição exponencial para as FDPs (Adams \& Papa, 2000).

Este método então foi aplicado aos dados hidro climatológicos da cidade de Campinas, obtidos pelo posto pluviográfico, localizado no Instituto Agronômico de Campinas (IAC), que possui uma estação automática hidrometeorológica. A metodologia trata estatisticamente os volumes, a duração, a intensidade média e o intervalo médio entre os eventos.

O parâmetro inter evento analisa estatísticamente sua frequência em relação ao volume, média e intensidade de chuva, evidenciando sua importância no entendimento e na caracterização do fenômeno, inclusive no cálculo dos volumes 
de detenção. Este método, diferentemente do Hidrograma Unitário, não adota valores médios de coeficientes, para a determinação destes hidrogramas de projeto, mas sim, são baseados em informações pluviográficas da região. Os parâmetros necessários para a determinação dos volumes dos reservatórios de detenção são obtidos por meio de uma simples função de transferência. Os parâmetros estatísticos são determinados a partir da distribuição de probabilidade das chuvas, associados com diferentes coeficientes de escoamento superficial arbitrados, de acordo com a ocupação atual e futura e, com a adoção de uma abstração inicial.

\section{OBJETIVOS}

Este estudo teve como objetivo averiguar a viabilidade do cálculo de pré-dimensionamento, para estudos de planejamento da macrodrenagem urbana, de volumes de bacias de detenção, mais conhecidos pelo nome popular de "piscinões" por meio do "Método de Análise Probabilística", que utiliza a teoria das funções de distribuições de probabilidades de diferentes parâmetros das chuvas em sistemas de drenagem urbana.

\section{FUNDAMENTAÇÃO TEÓRICA}

O método estatístico-analítico é baseado em um modelo analítico probabilístico, que utiliza a teoria da distribuição das probabilidades, na descrição dos fenômenos hidrológicos estudados por intermédio das Funções de Densidade de Probabilidade (FDP).

As FDPs das chuvas são transformadas em FDP de vazões com a utilização da função de transformação hidrológica, que retrata o escoamento de maneira simplificada e, com variáveis que possibilitam os cálculos desejados, mas sempre baseados nos dados reais medidos.

Segundo Adams \& Papa (2000) o método é mais vantajoso em relações a outros métodos pela rapidez com que se obtêm os resultados das análises por meio de equações simples oriundas do cálculo estatístico da FDP. Esta rapidez é importante em uma fase pré-dimensionamento, pois possibilita várias análises em pouco tempo, contribuindo para uma busca mais assertiva quanto à estrutura mais apropriada para um determinado sítio.

A metodologia possibilita ainda sua utilização numa etapa de busca de alternativas de possíveis soluções (planejamento), não só dos sistemas, mas também pode ser utilizado como ferramenta de controle e gerenciamento da drenagem urbana.

Dependendo da quantidade de variáveis que estão envolvidas no fenômeno, este método estatístico leva o estudo dos fenômenos às sínteses matemáticas, na forma de integrais simples, duplas ou triplas e ao serem processados os cálculos, estas integrais, permitem a estimação dos seguintes parâmetros:

- Média anual do volume de escoamento superficial;
- Frequência com que ocorre um certo volume de escoamento superficial;

- Média anual do volume de escoamento que infiltra (volume perdido);

- Média dos volumes do reservatório no início e no final da chuva;

- Frequência dos transbordamentos de um certo valor pré-determinado;

- Volume da bacia de detenção em função da vazão regularizada de saída e da probabilidade de ocorrência de um número escolhido de transbordamentos;

- Volume da bacia de detenção em função da vazão regularizada de saída e da probabilidade de uma taxa de retenção da onda de cheia que se queira escolher (definida por uma percentagem de retenção).

Para que seja possível a utilização deste modelo, os dados de entrada (chuvas) precisam de um tratamento prévio, assim os valores das alturas de chuvas são separados e classificados em eventos que o método define como chuvas, separadas por um intervalo mínimo de tempo entre eventos sucessivos, que são chamados de intervalos inter eventos.

O tempo de inter evento (TIE) é a definição de um período de intervalo seco entre as chuvas, sendo ele o critério de divisão entre uma chuva e outra. É importante ressaltar que este método é diferente dos métodos usualmente utilizados em dimensionamento hidráulico dos sistemas de drenagem urbana, que são baseados em métodos determinísticos de chuva e vazão, que utilizam as curvas de Intensidade Duração e Frequência (IDF) ou de Equações de Chuvas.

A principal diferença entre os métodos é que 
no caso das curvas IDF e as Equações de Chuvas, os cálculos são realizados a partir das análises das frequências das chuvas observadas em determinadas durações. Estas chuvas são determinadas/recortadas de chuvas de durações maiores, em intervalos contínuos de leitura de maior altura precipitada para aquela duração específica, enquanto que para o método analítico probabilístico, não interessa saber a duração das chuvas ou suas respectivas frequências, mas sim a definição do tempo mínimo de duração dos períodos secos, ou melhor, dos inter eventos das chuvas.

Uma vez definido esse tempo é realizada uma contagem de todos os eventos pluviosos, que ocorreram, no período analisado, separados por estes intervalos secos. Este parâmetro é muito importante para a análise da frequência estatística e é utilizado em quase todos os cálculos citados anteriormente.

\section{METODOLOGIA}

\section{Modelo Analítico Probabilístico}

Segundo Adams et al. (1986), a distribuição exponencial de probabilidade é a que mais se aproxima do comportamento dos histogramas de altura de chuva (ou volume da chuva) denominados por $(v)$, duração $\left({ }^{t}\right)$ e intensidade média $(i)$.

Assim, esses parâmetros estão representados por funções de distribuição exponencial de probabilidades e as equações das funções de densidade de probabilidade (FDP) podem ser reescritas como apresentadas na equação (1):

A equação (1) representa o volume (altura de chuva) definido por $\left({ }^{v}\right)$ em $(\mathrm{mm})$ :

$$
\text { FDP: } f(v)=\zeta * e^{-\zeta * v} \quad \text { Eq. } 1
$$

em que: $\zeta=\frac{1}{\bar{v}}\left(\mathrm{~mm}^{-1}\right) \mathrm{e}^{\bar{v}}=$ altura de chuva média, com intervalo de validade: $O \leq v \leq \infty$.

A duração da chuva $\left({ }^{t}\right)$, expressa em horas $(h)$ é definida pela equação (2):

FDP: $f(t)=\lambda * e^{-\lambda * t}$

Eq. 2

em que: ${ }^{\lambda=\frac{1}{\bar{t}}}\left(h^{-1}\right)$ e $\quad \bar{t}=$ tempo médio, com intervalo de validade $: 0 \leq i \leq \infty$.

Intensidade média da chuva, definida por $(i)$, expressa em $\left(m m \cdot h^{-1}\right)$, é representada pela equação (3):

$$
\text { FDP: } f(i)=\beta * e^{-\beta * i}
$$

Eq. 3

em que: ${ }^{\beta=\frac{1}{\bar{i}}}\left(m m \cdot h^{-1}\right) \mathrm{e}^{\bar{i}}=$ intensidade média.

Tempo de inter evento definido por $(b)$, expresso em horas $(h)$, tem por definição a equação (4):
FDP: $f(b)=\psi * e^{-\psi *(b-T I E)}$

Eq. 4

$$
\text { em que: } \psi=\frac{1}{\bar{b}-T I E}\left(h^{-1}\right) \text { e } \bar{b}=\text { TIE médio. }
$$

Volume do escoamento superficial, expresso em $(\mathrm{mm})$, é representado pela equação (5):

$$
v_{r}=\phi *\left(v-S_{d}\right) \quad \text { Eq. } 5
$$

quando: $v>S_{d}$, sendo que:

$v$ - volume do escoamento superficial, em

$v_{r} \mathrm{~mm}$;

$v$ - volume da chuva, em mm;

$S_{d}$ - volume total perdido nas depressões da bacia, em mm (abstração inicial);

$\phi$ - coeficiente de escoamento superficial, adimensional.

É importante observar que nem toda a chuva é transformada em escoamento superficial, pois parte dela é retida nas depressões, evapotranspirada e/ou infiltrada.

A parcela evapotranspirada é desprezível no intervalo de tempo do evento "chuva" considerada. Os outros dois parâmetros que são introduzidos no modelo matemático: coeficiente de escoamento superficial e abstração inicial, que tornam possível uma descrição do comportamento físico do escoamento superficial real, semelhante com o que é definido em métodos determinísticos e/ou modelos de transformação de chuva e vazão.

A figura 1 demonstra o esquema de drenagem proposto pelo método. A equação (5) retrata o fenômeno de forma simplificada. Primeiramente, após a abstração inicial (ou interceptação direta), a chuva $(\boldsymbol{v})$ preenche os volumes das depressões do terreno $\left(S_{d}\right)$, desta forma, o volume $\left(S_{d}\right)$ deve ser subtraído do volume inicial da chuva $\left({ }^{v}\right)$. Em seguida o escoamento superficial $\left({ }^{v_{r}}\right)$ é o resultado do produto do volume excedente da 
chuva $^{\left(v-S_{d}\right)}$ pelo coeficiente de escoamento superficial $(\phi)$, este é um número adimensional e menor que a unidade, a diferença $(1-\phi)$ é entendida como sendo o coeficiente do escoamento que traduz as perdas por infiltração, com uma taxa constante, iniciada somente após o preenchimento das depressões.

Desta forma, assume-se que o volume das perdas por infiltração vale $(1-\phi) *\left(v-S_{d}\right)$.

Este parâmetro pode ser considerado como semelhante àqueles valores utilizados pelo método racional que são definidos de acordo com a densidade de ocupação da bacia.

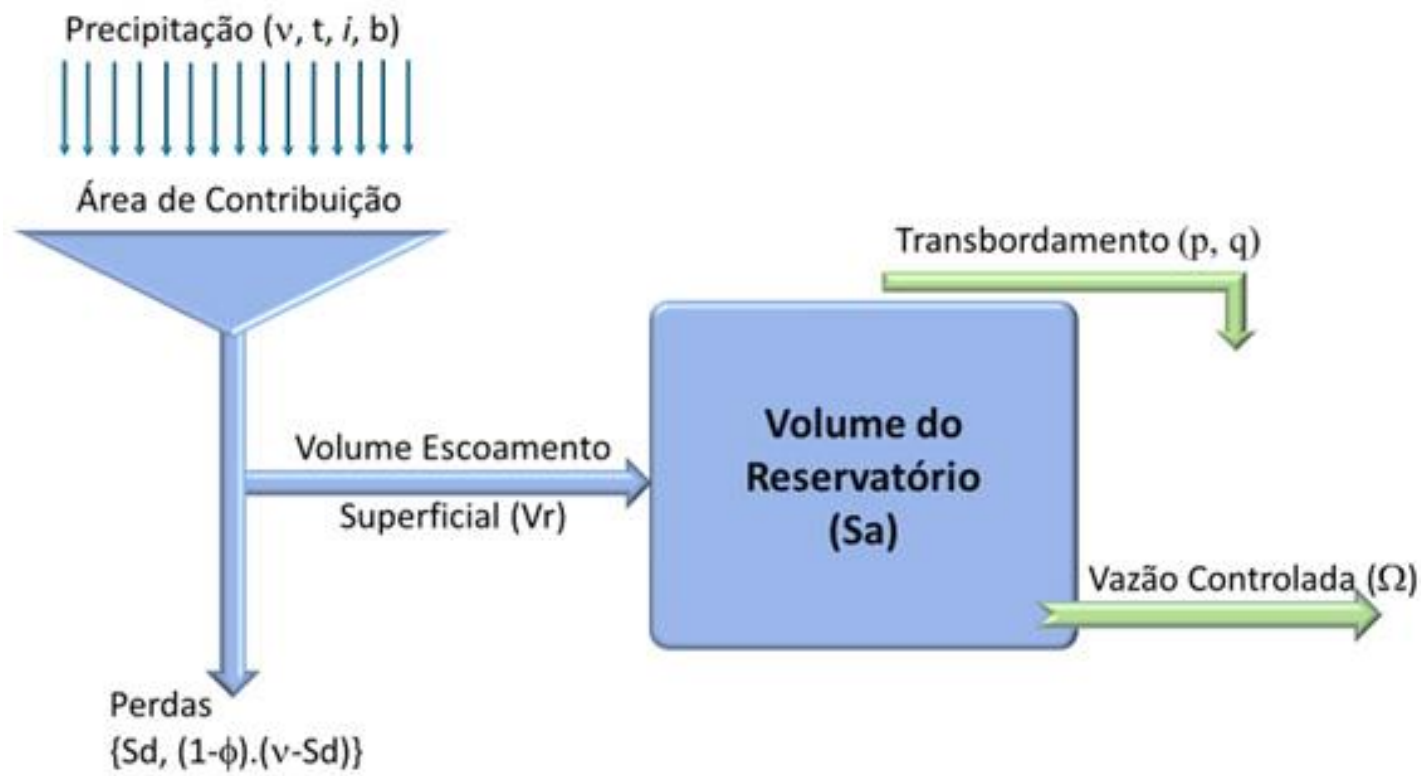

Figura 1 - Esquema de drenagem urbana utilizada no Modelo Analítico Probabilístico.

Considerando que ${ }^{v}$ é uma variável aleatória,

$v_{r}$ é fundamentalmente dependente de $v$, então, pode-se considerar que a aleatoriedade associada em $v$ é incorporada por $v_{r}$, por meio desta relação funcional. Desta forma, $v_{r}$ também será uma variável aleatória. Se a distribuição de probabilidade de ${ }^{v}$ for conhecida, então se torna possível derivar a distribuição de probabilidade $\mathrm{de}^{v_{r}}$ por meio de sua dependência funcional.

Baseado nestas premissas, o modelo assume as seguintes hipóteses:

- A vazão de saída é constante (simplificação do método para o planejamento da obra, mas que deverá ser devidamente determinada no dimensionamento no projeto executivo);

- A duração da chuva é praticamente igual à duração do escoamento superficial (simplificação do método para o planejamento, mas o cálculo deverá ser mais refinado no projeto executivo).

Como os volumes das depressões são pequenos nas pequenas bacias urbanizadas, estes são preenchidos antes do início do escoamento e antes que seja considerada a infiltração.
Apesar do coeficiente $\phi$ ser constante durante o evento da precipitação, na realidade ele varia em função das características geomor.fológicas da bacia e do grau de umidade inicial do solo, porém, considerando-se uma bacia impermeabilizada, a umidade inicial do solo será insignificante neste processo. Como o desempenho do sistema de drenagem é mais afetado pelo volume e pela duração do escoamento superficial do que o formato da onda de cheia, é assumido um hidrograma retangular para o cálculo. Considera-se que a chuva é uniformemente distribuída na bacia.

Nos casos de dimensionamento das estruturas hidráulicas, que necessitam do valor da vazão de pico, recomenda-se a utilização de outros métodos para tais finalidades. $\mathrm{O}$ volume máximo do reservatório de controle de cheia $(S a)$ é dado em milímetros como uma altura de precipitação uniforme em toda a bacia, que carrega uma simplificação da realidade. Este valor pode ser considerado como valor médio escoado nesta mesma duração da chuva. Este pode ser comparável com o fator de pico/média do método GRADEX, ou da correção de vazão média para vazão de pico, quando se trata de uma série de 
vazões médias diárias ao invés de vazões máximas instantâneas diárias. O mesmo será feito com a vazão de saída do reservatório $(\Omega \mathrm{em}$ $\mathrm{mm} / \mathrm{h}$ ), que é tida como constante, outra simplificação do método. Quando o reservatório encontrar-se completamente cheio e a vazão de entrada no reservatório ainda for maior que a de saída, então, neste caso, haverá o transbordo do excesso de volume ( $\mathrm{p} \mathrm{em} \mathrm{mm}$ ).

\section{Cálculo do Volume de Detenção}

É frequentemente utilizado para conhecer o volume do transbordamento para um intervalo específico de recorrência. O período de retorno (Tr) em anos para um transbordamento de magnitude PTr é representado pela equação (6):

em que:

$$
\operatorname{Tr}=\frac{1}{\theta \cdot G(P T r)} \quad \text { Eq. } 6
$$

$G(P T r)=$ probabilidade de ocorrer o transbordamento, associada ao período $\mathrm{Tr}$;

$\theta=$ número médio anual de eventos de
No que se refere a este estudo, devido à necessidade de comparação entre os procedimentos de cálculo, as precipitações foram calculadas para diferentes períodos de retorno correspondentes a: 1, 3, 5, 10, 25, 50 e 100 anos.

Para incorporar o parâmetro Tr no cálculo do volume de detenção a equação (6) foi rearranjada, e apresentada como equação (7):

$$
G(P T r)=\frac{1}{\theta \cdot T r} \quad \text { Eq. } 7
$$

A equação (8) define a probabilidade de uma precipitação provocar um transbordamento de um volume qualquer $\left(p_{0}>0\right)$.

Ao se adotar um determinado valor de $\mathrm{Tr}$, pode-se obter a probabilidade $G(P T r)$, assumindo $G(P T r)$ como sendo $G(0)$, podese substituir esse valor na equação (8). Dessa forma obtém-se uma relação em que o parâmetro $S a$ pode ser isolado. A equação (9) mostra o parâmetro $S a$ isolado como. chuva.

$$
\begin{aligned}
& \text { Para } T I E<\frac{S_{a}}{\Omega} \text {, tem-se } \\
& G(0)=\frac{\lambda / \Omega}{\lambda / \Omega+\zeta / \phi} \cdot \frac{(\psi / \Omega) \cdot e^{-(\zeta \Omega / \phi) \cdot T I E}+(\zeta / \phi) \cdot e^{-(\psi / \Omega+\zeta / \phi) \cdot S a+\psi \cdot T I E}}{\psi / \Omega+\zeta / \phi} \cdot e^{-\zeta S d} \\
& S a=\left\{\ln \left[\frac{1}{G(0) \cdot\left(\frac{(\lambda / \Omega)+(\zeta / \phi)}{\lambda / \Omega}\right) \cdot e^{-\zeta \cdot S d}-\left[\frac{(\psi / \Omega) \cdot e^{-(\zeta \Omega / \phi) \cdot T I E}}{(\psi / \Omega)+(\zeta / \phi)}\right]} \cdot \frac{\zeta / \phi}{(\psi / \Omega)+(\zeta / \phi)}\right]-\Psi \cdot T I E\right\} \cdot \frac{1}{(\psi / \Omega)+(\zeta / \phi)}
\end{aligned}
$$

Finalizando os procedimentos desta metodologia, a equação (9) possibilitará o cálculo dos valores dos volumes de detenção para a posterior análise e comparação.

Nos cálculos foram adotadas as seguintes premissas:

1. A vazão de fundo do reservatório foi assumida como sendo a vazão máxima do vertedouro, uma vez que a equação (9) é referente ao começo de uma chuva quando o reservatório está cheio;

2. O cálculo foi desenvolvido para os valores de TIE = 1h, 2h, 4h, 6h, 9h e $12 \mathrm{~h}$;

3. Foi assumido como coeficiente de escoamento superficial, $\phi=0,70$ e 0,90 , pelas condições atuais e futuras de impermeabilização desta bacia. O desenvolvimento na última década possibilitou uma urbanização indiscriminada na bacia do Ribeirão Anhumas, que possuía em torno de $70 \%$ da sua área urbanizada (dados referentes às pesquisas de campo empreendidas no ano de 2010).

Associado a este efeito de adensamento, que resulta em uma diminuição da vegetação na bacia, o adensamento provoca um aumento da temperatura urbana. $\mathrm{O}$ aumento da temperatura nas áreas urbanas favorece a ocorrência do fenômeno de convecção térmica, aumentando a frequência das precipitações convectivas. $\mathrm{O}$ aumento dessas chuvas de verão provoca a substancial elevação do número de ocorrência 
das enchentes urbanas.

Em vista ao exposto, acredita-se que em meados do ano de 2025 o coeficiente de escoamento superficial ( $\phi$ ) esteja em torno de 0,90

4. Para proceder ao cômputo desses parâmetros foi elaborado uma rotina de cálculo em linguagem Visual Basic no ambiente Access. O intervalo de discretização definido na estação hidro meteorológica automática do IACCampinas, para a leitura das alturas precipitadas é de 20 em 20 minutos. Porém, neste trabalho, para otimização da metodologia o intervalo mínimo dos TIEs adotados foi de uma hora e a múltiplos à 1 hora $(2,4,6,9$ e 12).

A priori poderiam ter sido utilizados TIEs variando de 20 em 20 minutos, mas não existe um critério padrão universalmente acordado a ser utilizado na discretização do intervalo de leitura dos dados de precipitação, conforme relatados por diversos pesquisadores (Burgueno et al., 1994; Dunkerley, 2008, Restro-Posada \& Eagleson, 1982), apenas a limitação pelos dados.

\section{ESTUDO DE CASO}

\section{Aspetos Geográficos e Gerais da Cidade de Campinas}

O município de Campinas está inserido na Unidade de Gerenciamento de Recursos Hídricos 05 (UGRHI 05), que corresponde às bacias hidrográficas dos rios Piracicaba, Capivari e Jundiaí, sendo um dos municípios mais populosos do estado de São Paulo. A população total de Campinas, segundo Censo de 2016 do IBGE (Instituto Brasileiro de Geografia e Estatística), é de 1.173.370 habitantes, sendo que cerca de $98 \%$ destes habitantes estão estabelecidos em área urbana.

As grandes taxas de crescimento populacional de Campinas e cidades em seu entorno, desde a década de 1940, levou ao processo de conturbação urbana e a necessidade de melhorar a logística de transporte e locomoção urbanas. Alguns problemas necessitavam de soluções conjuntas e, para possibilitar tais ações, foi necessária a criação, em 2000, da Região Metropolitana de Campinas (RMC), sendo Campinas sua sede.

Segundo estimativa do Instituto Brasileiro de Geografia e Estatística (IBGE) a RMC é a segunda maior Região Metropolitana do estado de São Paulo em população, contando com 3,1 milhões de habitantes para 2017, tendo gerado $8,92 \%$ do Produto Interno Bruto (PIB) estadual em 2015. Por este motivo, a cidade ocupa uma vasta região impermeabilizada, o que pode potencializar os problemas de alagamentos urbanos.

A região administrativa de Campinas tem a sua geologia composta por rochas do Embasamento Cristalino (predominam granitos e gnaisses) e por rochas sedimentares da Bacia do Paraná (onde se encontram arenitos, argilito, siltitos, quartzito, diabásios) (DAEE, 1981).
Solos estes que possuem boa capacidade de infiltração quando em estado natural, mas podem se tornar praticamente impermeáveis quanto compactados.

O Município de Campinas possui uma superfície de 794,57 km², divididos em 5 bacias principais, como ilustrado pela figura 2, são definidas por:

1. Bacia do Rio Jaguari, em que o Município de Campinas faz limite, a leste e noroeste, com os Municípios de Pedreira e Morungaba;

2. Bacia do Rio Atibaia, em que faz limite com o Município de Jaguariúna ao norte e Valinhos ao sul;

3. Bacia do Ribeirão Anhumas que nasce dentro do Município de Campinas e deságua no município de Paulínia a Oeste;

4. Bacia do Ribeirão Quilombo, que também nasce no Município de Campinas, desaguando no Município de Sumaré ao Oeste e Paulínia a norte e;

5. A bacia do Rio Capivari, que recebe suas águas a leste do Município de Valinhos e ao sul faz limite com os Municípios de Itupeva e Indaiatuba, fazendo limite com os Municípios de Monte Mor e Hortolândia a oeste.

Crescimento da região e enchentes no município de Campinas

Crescimento demográfico e a impermeabilização do solo

$\mathrm{O}$ crescimento da região de Campinas e principalmente do município de Campinas vêm apresentando, crescimentos populacionais superiores à média brasileira há décadas. A taxa de crescimento médio entre 1940 e 2010 foi de $3,07 \%$ ao ano, o que equivale a uma taxa média de crescimento de $35,33 \%$ por década (IBGE, 2018). De 2010 a 2017 o crescimento da população de Campinas saltou de 1.080.113, para 
1.194,094, um crescimento de 10,55\%, em sete anos e a uma taxa média anual de crescimento de $1,26 \%$ ao ano, conforme apresentado no Censo Demográfico do IBGE (revisão 2018) publicado em julho de 2018.
$\mathrm{O}$ crescimento das cidades modifica o uso e ocupação do solo, o que acarreta em maiores vazões para a mesma precipitação, pois se aumenta a impermeabilização, diminuindo-se a infiltração.

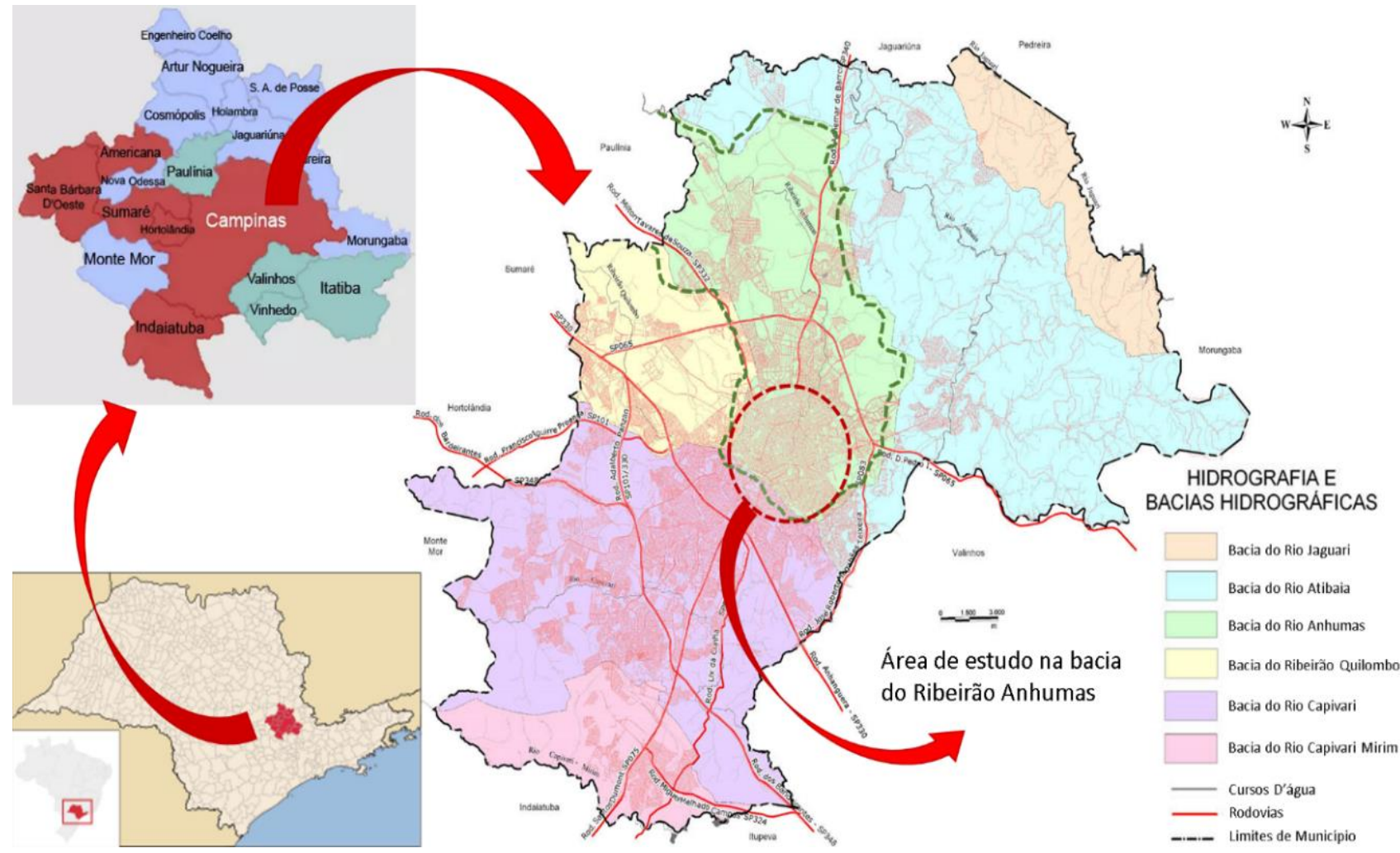

Figura 2 - Mapa com a localização da RMC no estado de São Paulo, Municípios que compõem a RMC e, no detalhe, o mapa das bacias hidrográficas no Município de Campinas - SP, com destaque à bacia do Ribeirão Anhumas e área de estudo, no alto Anhumas, com área de $68,54 \mathrm{~km}^{2}$. Fonte: SEMPLA.

As figuras 3 e 4 ilustram a densificação urbana sofrida pela cidade de Campinas ao longo das últimas décadas. A figura 3a ilustra a Praça do Viaduto Cury, que até o início da década de 1980 era bem arborizada com jardins e lagos no centro da cidade, sendo uma paisagem bastante bucólica para um centro de uma cidade de grande porte, de economia industrial bastante dinâmica e diversificada.

A mesma figura $3 \mathrm{~b}$ ilustra a substituição desta paisagem bucólica e pacífica para um dos pontos mais movimentados da cidade, em que foi substituída por um Terminal Central de ônibus urbano e barracas de comércio popular, tornado este local, do ponto de vista térmico, como um dos mais quentes da cidade.

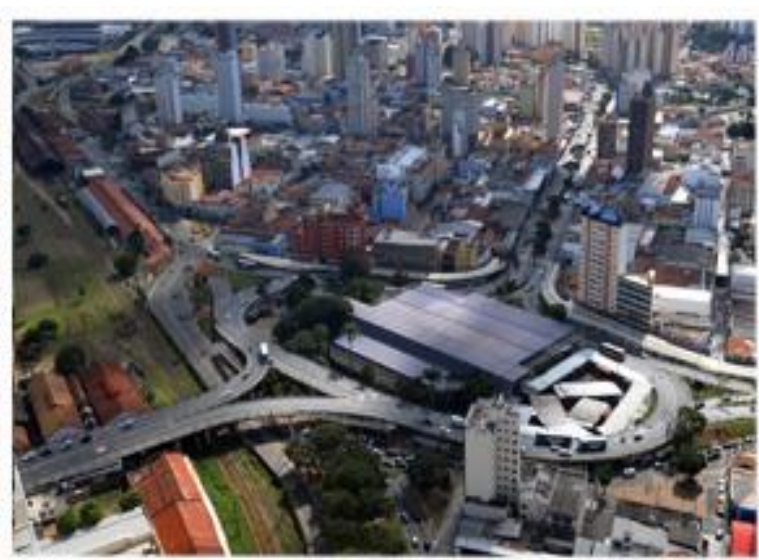

Figura 3 - Vista aérea da Praça do Viaduto Cury em Campinas antes e depois de sua substituição por um terminal central de ônibus urbano.a) Vista aérea da praça do Viaduto Cury na década de 1980. b) Vista aérea da praça do Viaduto Cury nos dias atuais. 

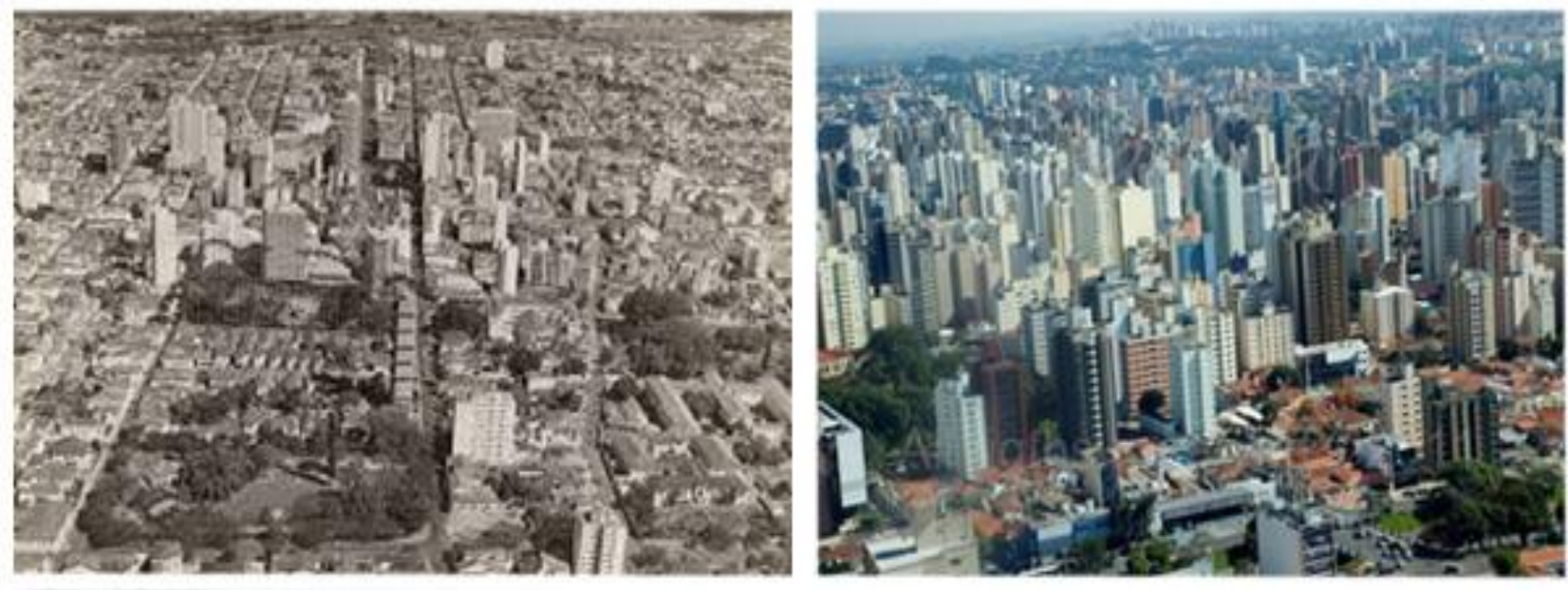

Figura 4 - Vista aérea da cidade de Campinas nas décadas de 1970 e 2010, evidenciando o adensamento populacional na área urbana.

A tabela 1 mostra a mudança no uso e ocupação do solo de rural para urbano nos últimos 110 anos, na bacia do Ribeirão Anhumas. A figura 4 ilustra a densificação populacional da cidade de Campinas em dois momentos, um no início da década de 1970 e outra no final da década de 2010, ilustrando a alteração do uso e ocupação do solo, de zona urbana predominantemente horizontal para zona urbana verticalizada, demonstrando o aumento da impermeabilização ocorrida em uma área já antropizada

Tabela 1 - Evolução dos usos urbanos e não urbanos entre 1907 e 2005. Fonte: Adaptada de Torres et al. (2014).

\begin{tabular}{c|c|c|c|c}
\hline \multirow{2}{*}{ Ano } & $\begin{array}{c}\text { Usos } \\
\text { Urbanos }\end{array}$ & Área & $\begin{array}{c}\text { Usos Não } \\
\text { Urbanos }\end{array}$ & Área \\
\cline { 2 - 5 } & $(\%)$ & $\left(\mathrm{km}^{2}\right)$ & $(\%)$ & $\left(\mathrm{km}^{2}\right)$ \\
\hline $\mathbf{1 9 0 7}$ & 5,0 & 7,50 & 95,0 & 142,50 \\
\hline $\mathbf{1 9 2 5}$ & 6,0 & 9,00 & 94,0 & 141,00 \\
\hline $\mathbf{1 9 6 2}$ & 20,9 & 31,35 & 79,1 & 118,65 \\
\hline $\mathbf{1 9 7 2}$ & 30,1 & 45,15 & 69,9 & 104,85 \\
\hline $\mathbf{2 0 0 5}$ & 49,0 & 73,50 & 51,0 & 76,50 \\
\hline
\end{tabular}

Esta é uma das razões do aumento das enchentes nas cidades da RMC, principalmente da cidade de Campinas que registou aumento da frequência das enchentes a partir de meados da década de 1970 até a presente data, mas com uma diminuição deste o ano de 2010.

\section{As cheias em Campinas}

As maiores e as mais avassaladoras enchentes na cidade de Campinas ocorreram, segundo as informações do Instituto Agronômico de Campinas (IAC) e Defesa Civil, em 01 de janeiro de 1990, em que a chuva, contada em um período de 24 horas, atingiu o acumulado de $138 \mathrm{~mm}$, o que correspondeu ao segundo maior volume pluviométrico dos últimos cem anos. A maior precipitação diária ocorreu no dia 17 de fevereiro de 2003, atingindo a altura de $141 \mathrm{~mm}$ e ficou marcada na memória da cidade pela morte de 6 pessoas e estragos nunca ocorridos antes na cidade de Campinas por uma enchente urbana, agravada pelo rompimento de dois açudes, atingindo o Parque Imperador, cortado pelo Ribeirão Anhumas.

A maior altura de chuva já verificada, para um curto intervalo de tempo, foi registrada pela Defesa Civil no dia 10 de fevereiro de 2015, registrando a marca de $112 \mathrm{~mm}$ de chuva, em apenas 2 horas (PMC, 2015).

\section{Bacia do Ribeirão Anhumas}

Para a aplicação do método proposto era preciso identificar uma bacia que reunisse características mais extremas em relação à ocupação urbana e que, ao mesmo tempo, possuísse um registro de ocorrências de enchentes urbanas, além da existência de um "piscinão".

Na cidade de Campinas, uma das bacias mais problemáticas, que reuniu todos estes requisitos foi uma sub-bacia do Ribeirão Anhumas, em sua porção urbana central, que possui uma área de contribuição de $68,54 \mathrm{~km}^{2}$ em sua parte mais alta e mais ocupada. A bacia do Ribeirão Anhumas possui uma área total de $150 \mathrm{~km}^{2}$, quando atinge sua foz, no município vizinho de Paulínia - SP, desaguando no Rio Atibaia e, que possui um pequeno piscinão (ou mini piscinão) com capacidade de retenção de $60.000 \mathrm{~m}^{3}$.

O Ribeirão Anhumas é afluente do Rio Atibaia e tem cerca de 50\% sua área impermeabilizada por densa ocupação urbana. A outra metade possui ocupação urbana de 
densidades média a muito baixa e/ou ocupação rural, sendo essa porção com as menores densidades e caracterizadas por baixas declividades que, por essa razão, é testemunha de inúmeros eventos de inundação, na parte norte do município.

A Bacia Hidrográfica do Ribeirão das Anhumas, em Campinas - SP ocupa a porção central do município e está circunscrita entre as coordenadas $22^{\circ} 52^{\prime}$ e $22^{\circ} 43^{\prime} \mathrm{S}$, e $47^{\circ} 06^{\prime}$ e $46^{\circ} 00^{\prime}$ W. Foram definidas, a partir das delimitações das bacias, de suas áreas de influência e da contribuição de drenagens de escoamento superficial, 11 sub bacias distintas (Figura 5). Destas 11 sub bacias identificadas por meio de inspeções de campo e da análise da cartografia disponível, foram definidas as sub bacias pertencentes aos dois córregos formadores do Ribeirão Anhumas: o Córrego Proença, com suas 7 sub bacias e o Córrego São Quirino, formado por 4 sub bacias, conforme apresentado na tabela 2. Das 7 sub bacias do Córrego Proença, somente 5 contribuem, em vazão para a seção de estudo.

Dentro da bacia do Córrego Anhumas, a Avenida José de Souza Campos é o principal eixo de ligação entre as zonas Sul e Norte da cidade. A Avenida Norte Sul, como também é conhecida, foi construída como via marginal ao córrego. Sob seu canteiro central escoam as águas do Córrego Proença, revezando-se trechos em canais e galerias, que irão formar o Ribeirão das Anhumas após a confluência com o Córrego São Quirino.

A figura 6 ilustra o trecho do Córrego Proença (Inferior) passando pela Avenida José de Sousa Campos em dois momentos distintos: um na década de 1990 e o outro nos dias atuais, ilustrando as canalizações antes e depois do seu confinamento. O trecho canalizado descarregará a vazão em um ponto mais a jusante da avenida, para o "mini piscinão", objeto de estudo deste artigo. Apesar das obras de drenagem terem sido concluídas em menos de 10 anos, os problemas de inundação da avenida continuam. O fato do seu confinamento e do aumento das impermeabilizações aumentaram ainda mais as inundações que já ocorriam conforme pode ser observado na mesma figura, tornando o problema cada vez mais insustentável, pois à proporção que a impermeabilidade é ampliada, novas obras, ou mesmo ampliações, serão necessárias (Tassi, 2014).

A figura 7 ilustra as enchentes em diferentes pontos da cidade, no caso da Avenida Princesa D'Oeste (Córrego Proença Superior) este trecho está a montante do trecho confinado e observado na figura 6 e no caso da Avenida Orozimbo Maia (Córrego Orozimbo Maia ou Córrego do Saneamento), onde as inundações ocorrem constantemente.

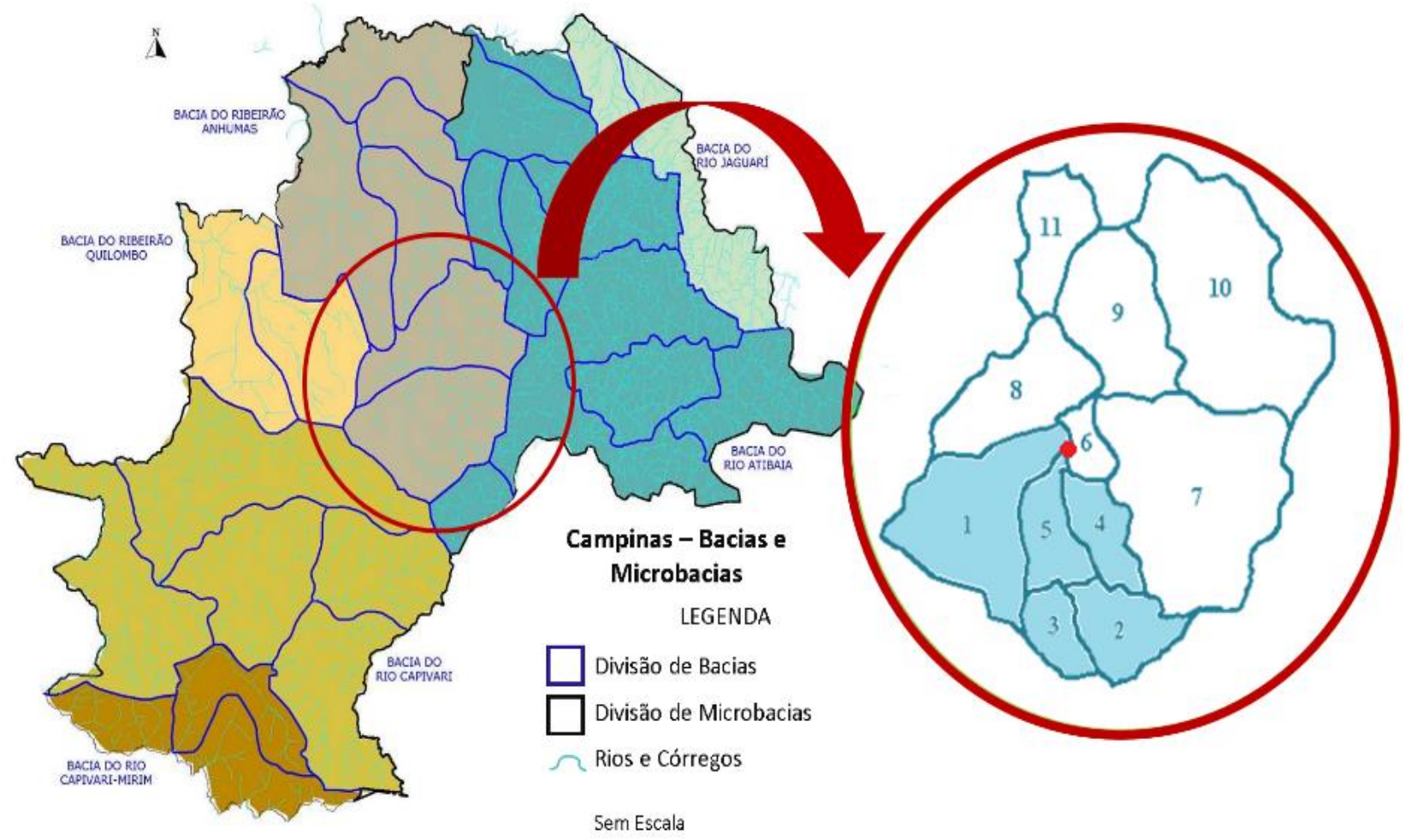

Figura 5 - Bacias Hidrográficas do Município de Campinas e divisão em sub-bacias da bacia hidrográfica do Ribeirão das Anhumas. 
Tabela 2 - Área das microbacias de drenagem.

\begin{tabular}{c|c|c|c}
\hline \multirow{2}{*}{ Macrobacia } & Bacia de Drenagem & Denominação & \multirow{2}{*}{ Área $\mathbf{( k m}^{\mathbf{2}}$} \\
\hline \multirow{4}{*}{ Córrego Proença } & 01 & Córrego Orozimbo Maia & 8,96 \\
\cline { 2 - 4 } & 02 & Córrego Vila Lemos & 3,65 \\
\cline { 2 - 4 } & 03 & Córrego Proença - Superior & 1,98 \\
\cline { 2 - 4 } & 04 & Córrego Oriente & 2,65 \\
\cline { 2 - 4 } & 05 & Córrego Proença - Inferior & 2,96 \\
\cline { 2 - 4 } & 06 & Córrego Anhumas - Superior & 1,37 \\
\hline \multirow{3}{*}{ Córrego São Quirino } & 07 & Córrego Angua Suja (da Lagoa) & 6,11 \\
\cline { 2 - 4 } & 08 & Córrego São Quirino & 1,03 \\
\cline { 2 - 4 } & 09 & Córrego da PUC & 3,79 \\
\cline { 2 - 4 } & 10 & & \\
\hline
\end{tabular}
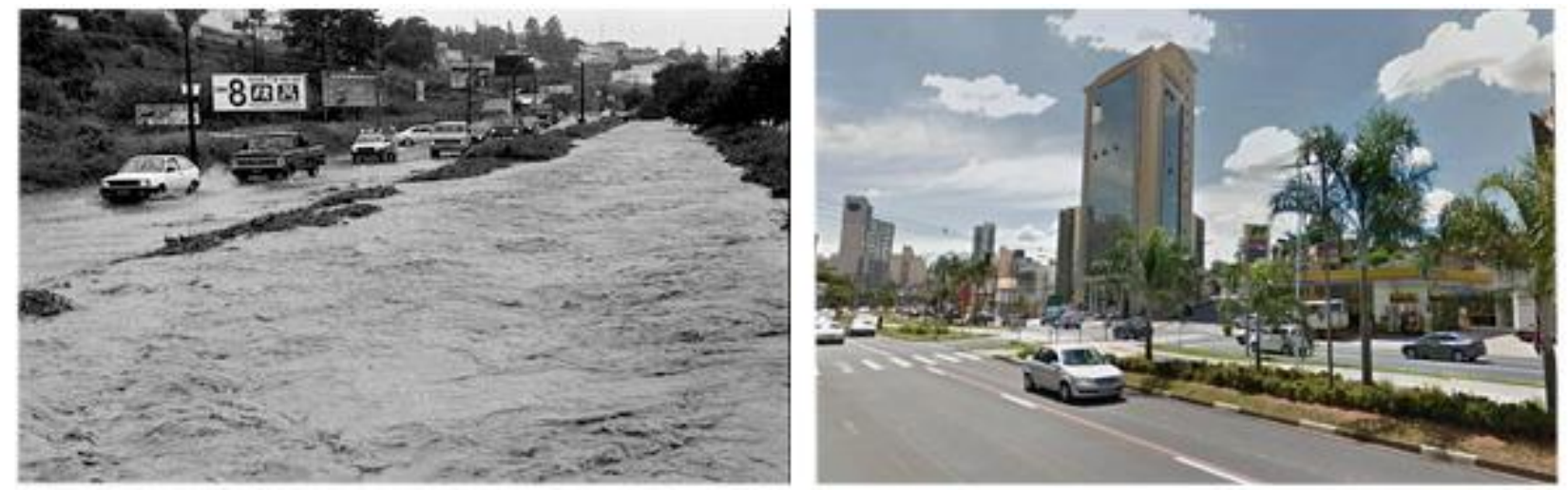

Figura 6 - Avenida José de Sousa Campos (Av. Norte Sul), enchente ocorrida no dia 05/02/1991 ainda sem canalização e após a canalização e o fechamento do córrego Ribeirão Anhumas, Campinas - SP. a) Avenida José de Sousa Campos sem canalização durante a inundação ocorrida em 05/02/1991. b) Avenida José de Sousa Campos nos dias atuais, totalmente canalizado e confinado.
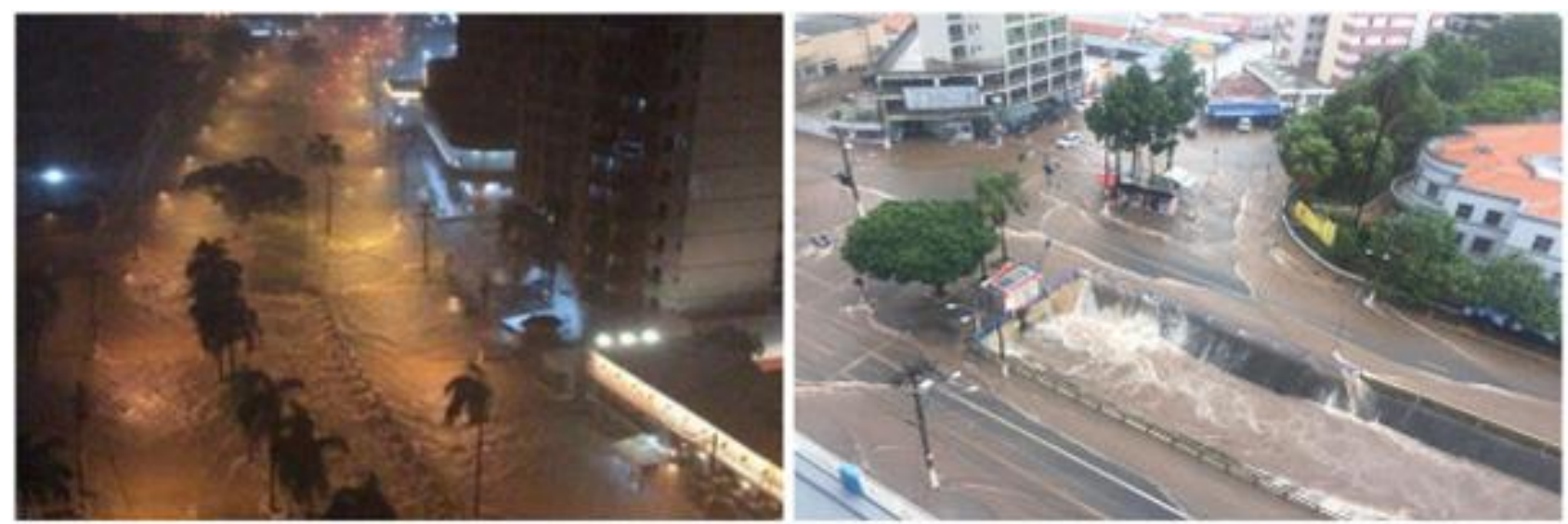

Figura 7 - Enchente na Avenida Princesa D’Oeste (Córrego Proença Superior) e Orozimbo Maia (Córrego Orozimbo Maia ou Córrego do Saneamento), córregos afluentes ao Ribeirão Anhumas, Campinas - SP.

A figura 8 ilustra o encontro das águas dos córregos da Avenida José de Sousa Campos e Orozimbo Maia, neste local foi construído um mini reservatório de detenção (Mini Piscinão), que não amortece as ondas de cheias, pois os córregos, além de chegarem em pontos diametralmente opostos, a saída é transversal ao alinhamento dos dois córregos, criando correntes secundárias, que dificultam o escoamento. Este fenômeno provoca perdas de cargas o que diminui a vazão de saída, provocando o aumento do nível da água no "mini piscinão". O reservatório enche rapidamente, afoga o bueiro e dificulta a saída da água para o Ribeirão Anhumas.

Este mini piscinão possui uma área média de $14.000 \mathrm{~m}^{2}$, e altura média entre 4,0 a $4,5 \mathrm{~m}$ de profundidade, o que lhe confere um volume aproximado de $60.000 \mathrm{~m}^{3}$, que é um volume muito aquém do necessário, pois seu transbordamento é verificado em uma frequência de 4 a 5 vezes ao ano em média. 

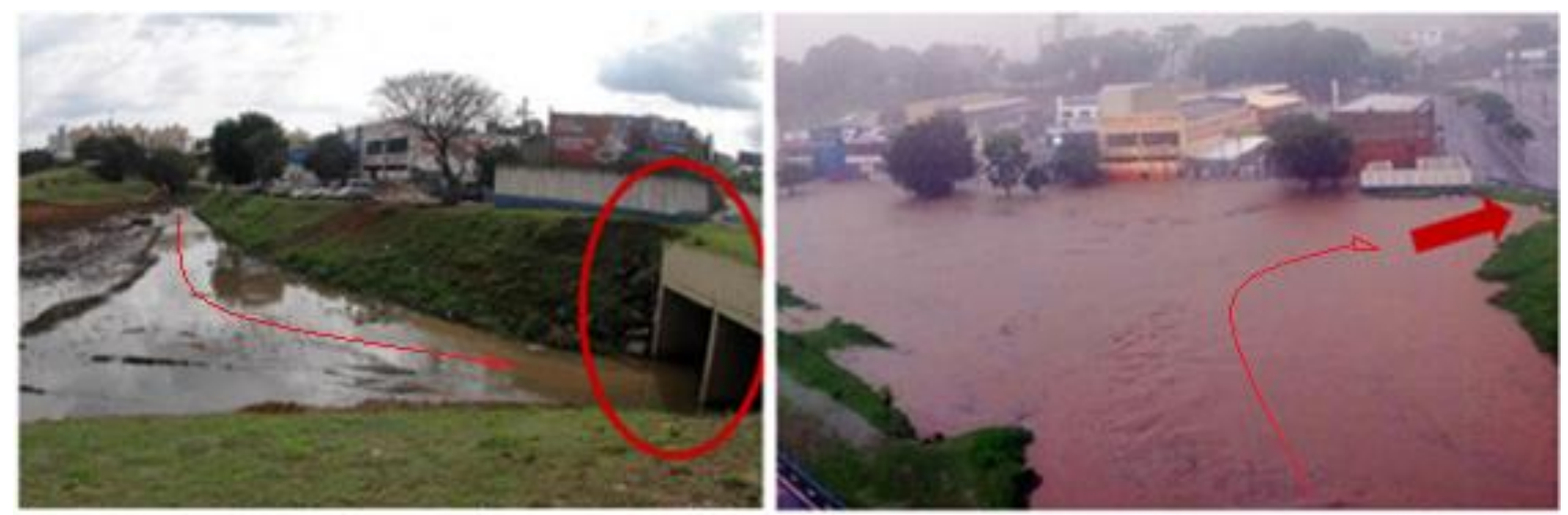

Figura 8 - Local de contribuição dos Córregos do Proença e do Orozimbo no Ribeirão das Anhumas (mini piscinão). Detalhe do exutório do mini piscinão a montante do Ribeirão das Anhumas. a) Vista chegada Córrego Orozimbo Maia de cima para a direita, em direção ao bueiro. b) Chegada das águas do Córrego Proença na parte de baixo e para a direita da figura.

\section{Dados Pluviográficos}

Com relação ao clima, a região de Campinas apresenta verões úmidos, cuja precipitação total mensal pode apresentar valores superiores a 200 $\mathrm{mm}$, enquanto que, no inverno seco, os índices pluviométricos totais mensais atingem valores da ordem de $20 \mathrm{~mm}$. Os dados dos valores horários dos elementos hidrometereológicos do posto pluviográfico da Secretaria de Agricultura e Abastecimento, localizados no IAC-CIIAGRO (Instituto Agronômico de Campinas) encontram-

se em forma digital, discretizados em intervalos de 20 minutos, sendo sua latitude $22^{\circ} 54^{\prime} \mathrm{S}$ e longitude $47^{\circ} 05^{\prime} \mathrm{W}$ e altitude 669 metros ao nível do mar, operando desde 06/02/2002 e permanece em operação. A formatação dos dados disponíveis em formato digital pode ser ilustrada conforme apresentado na figura 9.

Com estes dados de chuvas é possível a obtenção dos parâmetros exigidos pelo modelo analítico probabilístico, para o cálculo dos volumes das bacias de detenção.

\begin{tabular}{|c|c|c|c|c|}
\hline $\begin{array}{l}\text { Prefixo: } \\
\text { Nome: }\end{array}$ & \multicolumn{4}{|c|}{$\begin{array}{l}\text { Instituto Agronômico - CIIAGRO / SISGEMA } \\
\text { Fazenda IAC }\end{array}$} \\
\hline Entidade: & \multicolumn{4}{|c|}{ Instituto Agronômico de Campinas } \\
\hline Município: & \multicolumn{4}{|c|}{ Campinas } \\
\hline Altitude (m): & \\
\hline Latitude: & \multicolumn{4}{|c|}{$22^{\circ} 54 \mathrm{~s}$} \\
\hline Longitude: & \multicolumn{4}{|c|}{$47^{\circ} 05^{\prime} \mathrm{W}$} \\
\hline Data inicial: & \multicolumn{4}{|c|}{$06 / 02 / 2002$} \\
\hline Data final: & \multicolumn{4}{|c|}{ posto em atividade } \\
\hline \multicolumn{5}{|c|}{ Eventos de chuva: altura precipitada (mm) } \\
\hline Data & Hora & $00^{\prime}$ & $20^{\prime}$ & $40^{\prime}$ \\
\hline $06 / 02 / 2002$ & $00: 00$ & 0,000 & 0,000 & 0,000 \\
\hline $06 / 02 / 2002$ & $01: 00$ & 0,000 & 0,000 & 0,000 \\
\hline $06 / 02 / 2002$ & $02: 00$ & 0,000 & 0,000 & 0,000 \\
\hline $06 / 02 / 2002$ & $03: 00$ & 0,000 & 0,000 & 0,000 \\
\hline $06 / 02 / 2002$ & $04: 00$ & 0,000 & 0,000 & 0,000 \\
\hline $06 / 02 / 2002$ & $05: 00$ & 0,000 & 0,000 & 0,000 \\
\hline $06 / 02 / 2002$ & $19: 00$ & 0,000 & 0,000 & 0,508 \\
\hline $06 / 02 / 2002$ & $20: 00$ & 1,270 & 1,016 & 1,778 \\
\hline $06 / 02 / 2002$ & $21: 00$ & 0,762 & 0,000 & 0,000 \\
\hline $06 / 02 / 2002$ & $22: 00$ & 0,000 & 0,000 & 0,000 \\
\hline $06 / 02 / 2002$ & $23: 00$ & 0,254 & 0,762 & 0,508 \\
\hline $07 / 02 / 2002$ & $00: 00$ & 0,508 & 0,254 & 0,508 \\
\hline $07 / 02 / 2002$ & $01: 00$ & 0,000 & 0,762 & 0,000 \\
\hline $07 / 02 / 2002$ & $02: 00$ & 0,000 & 0,000 & 0,000 \\
\hline
\end{tabular}

Figura 9 - Formatação dos dados pluviográficos do banco de dados do IAC, para o posto pluviográfico, localizado em Campinas-SP.

\section{RESULTADOS SOBRE O MODELO ANALÍTICO-PROBABILÍSTICO}

\section{Cálculo dos Parâmetros:}

O programa Access (pacote Office da Microsoft) foi utilizado para o tratamento dos dados de chuva e, a programação para a leitura e obtenção dos resultados, na plataforma em VB (Visual Basic), obtendo-se assim os seguintes 
parâmetros para cada um dos inter eventos avaliados:

- Número de precipitações: $\quad \theta$ (anual);

- Média de altura da precipitação: $\bar{v}(\mathrm{~mm})$;

- Inverso da média das alturas das precipitações: $\zeta\left(\mathrm{mm}^{-1}\right)$;

- Média da duração de precipitação: t (h);

- Inverso da média das durações das precipitações: $\lambda\left(\mathrm{h}^{-1}\right)$;

- Média das intensidades: $\mathrm{i}\left(\mathrm{mm} \cdot \mathrm{h}^{-1}\right)$;

- Média dos tempos de inter eventos: b (h);

- Inverso da média dos tempos de inter eventos: $\Psi \mathrm{a}\left(\mathrm{h}^{-1}\right)$.

A tabela 3 apresenta os resultados obtidos por meio da utilização do programa para cada inter evento avaliado.

\section{Dimensionamento do Reservatório}

Por meio da equação (9) foi possível obter os resultados dos volumes de detenções. Esses volumes foram calculados para vários TIE (tempo de inter evento).
O parâmetro TIE traduz a consideração de precipitações sequenciais como sendo apenas uma precipitação.

No que se refere ao coeficiente de escoamento superficial $(\varnothing)$, foram adotados dois valores, a saber: $\varnothing=0,70$ (atual) e $\varnothing=0,90$ (o primeiro corresponde a uma bacia com taxas médias a alta de ocupação, e a segunda com taxas altas de ocupação), no intuito de estudar a sensibilidade da equação (9) em relação a esse parâmetro, para ambos, foram utilizados como volume total das depressões da bacia $S d(\Phi)$ o valor de $0,50 \mathrm{~mm}$ e a vazão controlada de descarga da bacia de detenção $\Omega=19,05 \mathrm{~mm} / \mathrm{h}$, os resultados finais obtidos em mm e em $\mathrm{m}^{3}$ são referentes às áreas de armazenamento necessárias para as bacias de drenagem 01, 02, 03, 04 e 05 da tabela 2, que totalizam uma área total de $20,2 \mathrm{~km}^{2}$. O valor de $\Omega=19,05 \mathrm{~mm} / \mathrm{h}$ foi calculado partindo-se da capacidade máxima, a jusante do Ribeirão Anhumas, em seu ponto mais crítico que corresponde a uma vazão máxima aproximada de $100,00 \mathrm{~m}^{3} / \mathrm{s}$.

Tabela 3 - Valores dos parâmetros para cada inter evento avaliado.

\begin{tabular}{c|c|c|c|c|c|c|c}
\hline \multicolumn{2}{c|}{ Parâmetro } & \multicolumn{5}{c}{ Intervalos de Inter Eventos em horas } \\
\hline $\mathbf{T I E}(\mathbf{h})$ & $\begin{array}{c}\text { Tempo de Inter } \\
\text { Evento }\end{array}$ & $\mathbf{1}$ & $\mathbf{2}$ & $\mathbf{4}$ & $\mathbf{6}$ & $\mathbf{9}$ & $\mathbf{1 2}$ \\
\hline $\boldsymbol{\theta}(\mathbf{a n u a l )}$ & $\begin{array}{c}\text { Número de } \\
\text { Precipitações }\end{array}$ & 238 & 188 & 148 & 126 & 108 & 93 \\
\hline$\overline{\boldsymbol{\nu}}(\mathbf{m m})$ & $\begin{array}{c}\text { Média das Alturas } \\
\text { das Precipitações }\end{array}$ & 5,634196 & 7,127316 & 9,067147 & 10,614061 & 12,412838 & 14,474395 \\
\hline $\boldsymbol{\zeta}\left(\mathbf{m m}^{-\mathbf{1}}\right)$ & $\begin{array}{c}\text { Inverso da Média } \\
\text { das Alturas das } \\
\text { Precipitações }\end{array}$ & 0,177488 & 0,140305 & 0,110288 & 0,094215 & 0,080562 & 0,069088 \\
\hline $\mathbf{t}(\mathbf{h})$ & $\begin{array}{c}\text { Média das } \\
\text { Durações das } \\
\text { Precipitações }\end{array}$ & 1,558283 & 2,304923 & 3,676471 & 5,106029 & 7,184495 & 10,078486 \\
\hline $\mathbf{i}(\mathbf{m m} \cdot \mathbf{h}-$ & $\begin{array}{c}\text { Média das } \\
\text { Intensidades das } \\
\text { Precipitações }\end{array}$ & 3,225144 & 3,260013 & 3,148828 & 3,100104 & 3,048469 & 2,921891 \\
\hline $\mathbf{b}(\mathbf{h})$ & $\begin{array}{c}\text { Média dos Tempos } \\
\text { de Inter Eventos }\end{array}$ & 35,142299 & 44,121693 & 55,386011 & 64,032888 & 73,67474 & 84,206260 \\
\hline $\mathbf{\Psi a}\left(\mathbf{h}^{-1}\right)$ & $\begin{array}{c}\text { Inverso da Média } \\
\text { dos Tempos de } \\
\text { Inter Eventos }\end{array}$ & 0,029289 & 0,023741 & 0,019461 & 0,017232 & 0,015463 & 0,013849 \\
\hline $\boldsymbol{\lambda}\left(\mathbf{h}^{-1}\right)$ & $\begin{array}{c}\text { Inverso da Média } \\
\text { das Durações das } \\
\text { Precipitações }\end{array}$ & 0,641732 & 0,433854 & 0,272000 & 0,195847 & 0,139189 & 0,099221 \\
\hline
\end{tabular}

As tabelas 4 e 5 fornecem os valores dos volumes de chuva $S a$ em $(\mathrm{mm})$ que devem ser armazenados, evitando as inundações e, seu respectivo volume $V a \mathrm{em}\left(\mathrm{m}^{3}\right)$, utilizando um coeficiente de escoamento superficial $(\varnothing)=$ 0,70 .

As tabelas 6 e 7 fornecem os valores dos volumes de chuva $S a$ em (mm) que devem ser armazenados, evitando as inundações e, seu respectivo volume $V a \mathrm{em}\left(\mathrm{m}^{3}\right)$, utilizando um coeficiente de escoamento superficial $(\varnothing)=$ 0,90 .

Para melhor visualização dos valores calculados dos volumes de detenção foi 
construída a figura 11 para o coeficiente de escoamento superficial $(\varnothing)$ correspondente a 0,90 ou $\varnothing=0,90$. O que pode ser observado pelos resultados do método Analítico Probabilístico, o volume mínimo necessário para o amortecimento das vazões de enchentes, para $(\varnothing)=0,70$, seria de $268.000 \mathrm{~m}^{3}$, para um período de retorno de apenas 1 ano.

Tabela 4 - Volume do Reservatório de Detenção para cada $S a$ em $(\mathrm{mm})$ e o valor $V a$ em $\left(\mathrm{m}^{3}\right)$, em função do tempo de inter evento (TIE) para valores fixados de Tempo de Recorrência (Tr) e coeficiente de escoamento superficial $(\varnothing)=0,70$.

\begin{tabular}{c|c|c|c|c|c|c|c|c}
\hline $\begin{array}{c}\text { Volume de } \\
\text { Detenção }\end{array}$ & \multicolumn{2}{|c|}{$\begin{array}{c}\text { Tr=1 } \\
\emptyset=\mathbf{0 , 7 0}\end{array}$} & \multicolumn{2}{c|}{$\begin{array}{c}\text { Tr=3 } \\
\emptyset=\mathbf{0 , 7 0}\end{array}$} & \multicolumn{2}{c|}{$\begin{array}{c}\text { Tr=5 } \\
\emptyset=\mathbf{0 , 7 0}\end{array}$} & \multicolumn{2}{c}{$\begin{array}{c}\text { Tr= 10 } \\
\emptyset=\mathbf{0 , 7 0}\end{array}$} \\
\hline TIE (h) & $S a(\mathbf{m m})$ & $V a\left(\mathbf{m}^{3}\right)$ & $S a(\mathbf{m m})$ & $V a\left(\mathbf{m}^{3}\right)$ & $S a(\mathbf{m m})$ & $V a\left(\mathbf{m}^{3}\right)$ & $S a(\mathbf{m m})$ & $V a\left(\mathbf{m}^{3}\right)$ \\
\hline $\mathbf{1}$ & 13,27 & 267.965 & 17,58 & 355.194 & 19,60 & 395.879 & 22,34 & 451.355 \\
\hline $\mathbf{2}$ & 14,73 & 297.518 & 20,18 & 407.565 & 22,71 & 458.740 & 26,15 & 528.195 \\
\hline $\mathbf{4}$ & 15,64 & 315.945 & 22,57 & 455.890 & 25,79 & 520.961 & 30,16 & 609.257 \\
\hline $\mathbf{6}$ & 15,70 & 317.201 & 23,81 & 480.983 & 27,58 & 557.137 & 32,70 & 660.472 \\
\hline $\mathbf{9}$ & 15,17 & 306.352 & 24,64 & 497.827 & 29,05 & 586.858 & 35,03 & 707.666 \\
\hline $\mathbf{1 2}$ & 14,09 & 284.526 & 25,14 & 507.732 & 30,27 & 611.518 & 37,24 & 752.345 \\
\hline
\end{tabular}

Tabela 5 - Volume do Reservatório de Detenção para cada Sa em (mm) e o valor Va em ( $\left.\mathrm{m}^{3}\right)$, em função do tempo de inter evento (TIE) para valores fixados de Tempo de Recorrência (Tr) e coeficiente de escoamento superficial $(\varnothing)=0,70$.

\begin{tabular}{c|c|c|c|c|c|c}
\hline $\begin{array}{c}\text { Volume de } \\
\text { Detenção }\end{array}$ & \multicolumn{2}{|c|}{$\begin{array}{c}\text { Tr=25 } \\
\emptyset=\mathbf{0 , 7 0}\end{array}$} & \multicolumn{2}{c}{$\begin{array}{c}\text { Tr= 50 } \\
\emptyset=\mathbf{0 , 7 0}\end{array}$} & \multicolumn{2}{c}{$\begin{array}{c}\text { Tr= 100 } \\
\emptyset=0,70\end{array}$} \\
\hline TIE (h) & $S a(\mathbf{m m})$ & $V a\left(\mathbf{m}^{3}\right)$ & $S a(\mathbf{m m})$ & $V a\left(\mathbf{m}^{3}\right)$ & $S a(\mathbf{m m})$ & $V a\left(\mathbf{m}^{3}\right)$ \\
\hline $\mathbf{1}$ & 26,02 & 525.703 & 28,89 & 583.668 & 31,94 & 645.091 \\
\hline $\mathbf{2}$ & 30,70 & 620.060 & 34,14 & 689.638 & 37,59 & 759.371 \\
\hline $\mathbf{4}$ & 35,94 & 725.978 & 40,31 & 814.275 & 44,68 & 902.574 \\
\hline $\mathbf{6}$ & 39,46 & 797.074 & 44,57 & 900.409 & 49,69 & 1.003 .744 \\
\hline $\mathbf{9}$ & 42,94 & 867.364 & 48,92 & 988.172 & 54,90 & 1.108 .979 \\
\hline $\mathbf{1 2}$ & 46,46 & 938.509 & 53,43 & 1.079 .337 & 60,40 & 1.220 .165 \\
\hline
\end{tabular}

Tabela 6 - Volume do Reservatório de Detenção para cada Sa em (mm) e o valor Va em ( $\left.\mathrm{m}^{3}\right)$, em função do tempo de inter evento (TIE) para valores fixados de Tempo de Recorrência (Tr) e coeficiente de escoamento superficial $(\varnothing)=0,90$.

\begin{tabular}{|c|c|c|c|c|c|c|c|c|}
\hline \multirow{2}{*}{$\begin{array}{c}\begin{array}{l}\text { Volume de } \\
\text { Detenção }\end{array} \\
\text { TIE (h) }\end{array}$} & \multicolumn{2}{|c|}{$\begin{array}{c}\operatorname{Tr}=1 \\
\emptyset=0,90\end{array}$} & \multicolumn{2}{|c|}{$\begin{array}{c}\operatorname{Tr}=3 \\
\emptyset=0,90\end{array}$} & \multicolumn{2}{|c|}{$\begin{array}{c}\operatorname{Tr}=5 \\
\emptyset=0,90\end{array}$} & \multicolumn{2}{|c|}{$\begin{array}{l}\mathrm{Tr}=10 \\
\emptyset=\mathbf{0 , 9 0}\end{array}$} \\
\hline & $S a(\mathbf{m m})$ & $V a\left(\mathbf{m}^{3}\right)$ & $S a(\mathrm{~mm})$ & $V a\left(\mathbf{m}^{3}\right)$ & $S a(\mathbf{m m})$ & $V a\left(\mathbf{m}^{3}\right)$ & $S a(\mathrm{~mm})$ & $V a\left(\mathbf{m}^{3}\right)$ \\
\hline 1 & 18,14 & 366.502 & 23,74 & 479.575 & 26,38 & 532.927 & 30,05 & 607.050 \\
\hline 2 & 20,31 & 410.295 & 27,31 & 551.657 & 30,57 & 617.460 & 35,00 & 706.909 \\
\hline 4 & 21,90 & 442.418 & 30,79 & 622.021 & 34,93 & 705.534 & 40,54 & 818.858 \\
\hline 6 & 22,32 & 450.928 & 32,73 & 661.104 & 37,57 & 758.831 & 44,13 & 891.438 \\
\hline 9 & 22,03 & 445.069 & 34,20 & 690.759 & 39,85 & 804.999 & 47,53 & 960.013 \\
\hline 12 & 21,10 & 426.317 & 35,28 & 712.698 & 41,87 & 845.858 & 50,82 & 1.026 .545 \\
\hline
\end{tabular}


Tabela 7 - Volume do Reservatório de Detenção para cada $S a$ em $(\mathrm{mm})$ e o valor $V a$ em $\left(\mathrm{m}^{3}\right)$, em função do tempo de inter evento (TIE) para valores fixados de Tempo de Recorrência $(\mathrm{Tr})$ e coeficiente de escoamento superficial $(\varnothing)=$ 0,90. Para melhor visualização dos valores calculados dos volumes de detenção foi elaborada a figura 10 para 0 coeficiente de escoamento superficial $(\varnothing)$ correspondente 0,70 ou $\varnothing=0,70$.

\begin{tabular}{|c|c|c|c|c|c|c|}
\hline \multirow{2}{*}{$\begin{array}{c}\begin{array}{c}\text { Volume de } \\
\text { Detenção }\end{array} \\
\text { TIE }(h)\end{array}$} & \multicolumn{2}{|c|}{$\begin{array}{l}\operatorname{Tr}=25 \\
\emptyset=0,90\end{array}$} & \multicolumn{2}{|c|}{$\begin{array}{l}\operatorname{Tr}=50 \\
\varnothing=0,90\end{array}$} & \multicolumn{2}{|c|}{$\begin{array}{c}\mathrm{Tr}=100 \\
\varnothing=0,90\end{array}$} \\
\hline & $S a(\mathrm{~mm})$ & $V a\left(\mathrm{~m}^{3}\right)$ & $S a(\mathrm{~mm})$ & $V a\left(\mathrm{~m}^{3}\right)$ & $S a(\mathrm{~mm})$ & $V a\left(\mathrm{~m}^{3}\right)$ \\
\hline 1 & 35,25 & 712.072 & 39,90 & 806.079 & 47,10 & 951.483 \\
\hline 2 & 40,88 & 825.740 & 45,38 & 916.602 & 49,97 & 1.009 .299 \\
\hline 4 & 47,95 & 968.680 & 53,57 & 1.082 .043 & 59,18 & 1.195 .454 \\
\hline 6 & 52,81 & 1.066 .736 & 59,37 & 1.199 .345 & 65,94 & 1.331 .958 \\
\hline 9 & 57,67 & 1.164 .930 & 65,34 & 1.319 .944 & 73,02 & 1.474 .958 \\
\hline 12 & 62,64 & 1.265 .400 & 71,59 & 1.446 .087 & 80,53 & 1.626 .773 \\
\hline
\end{tabular}

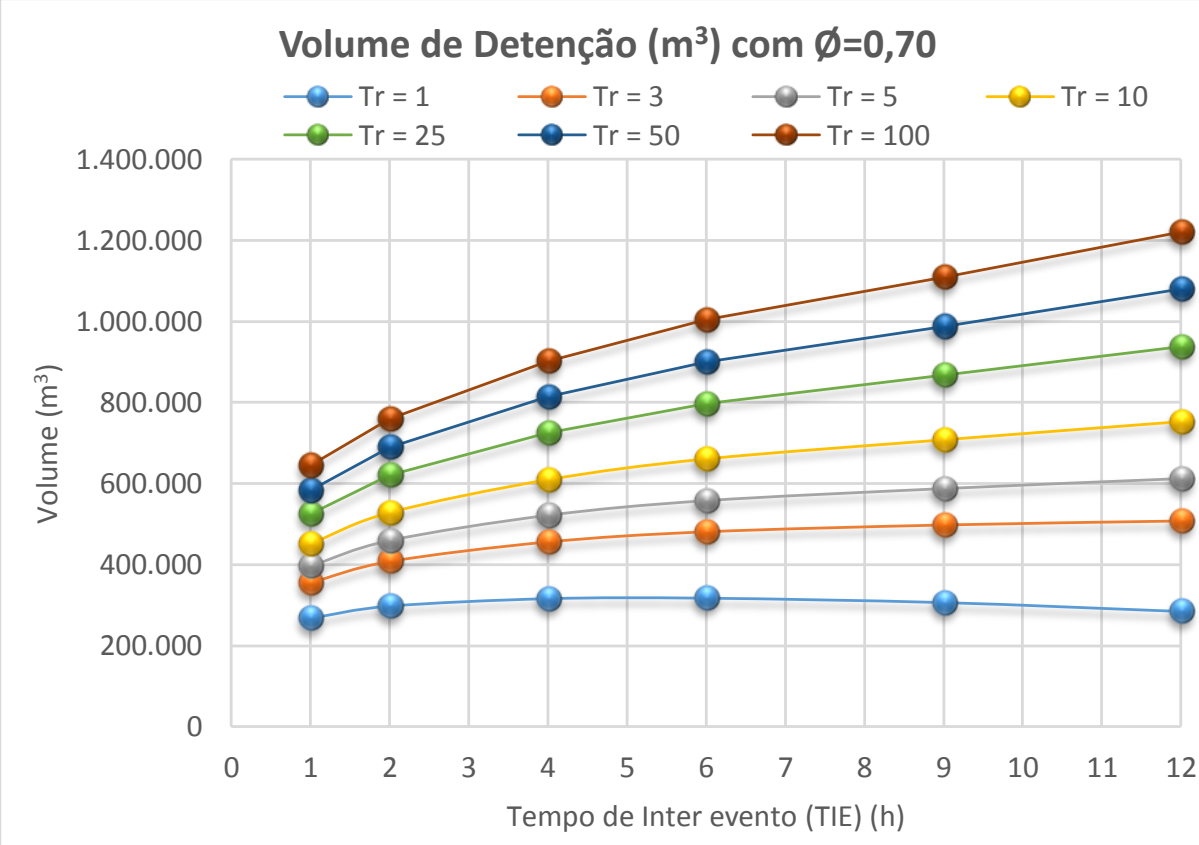

Figura 10 - Volume de Detenção do Reservatório $V a\left(\mathrm{~m}^{3}\right)$ com coeficiente de escoamento Superficial $(\varnothing)=0,70$.

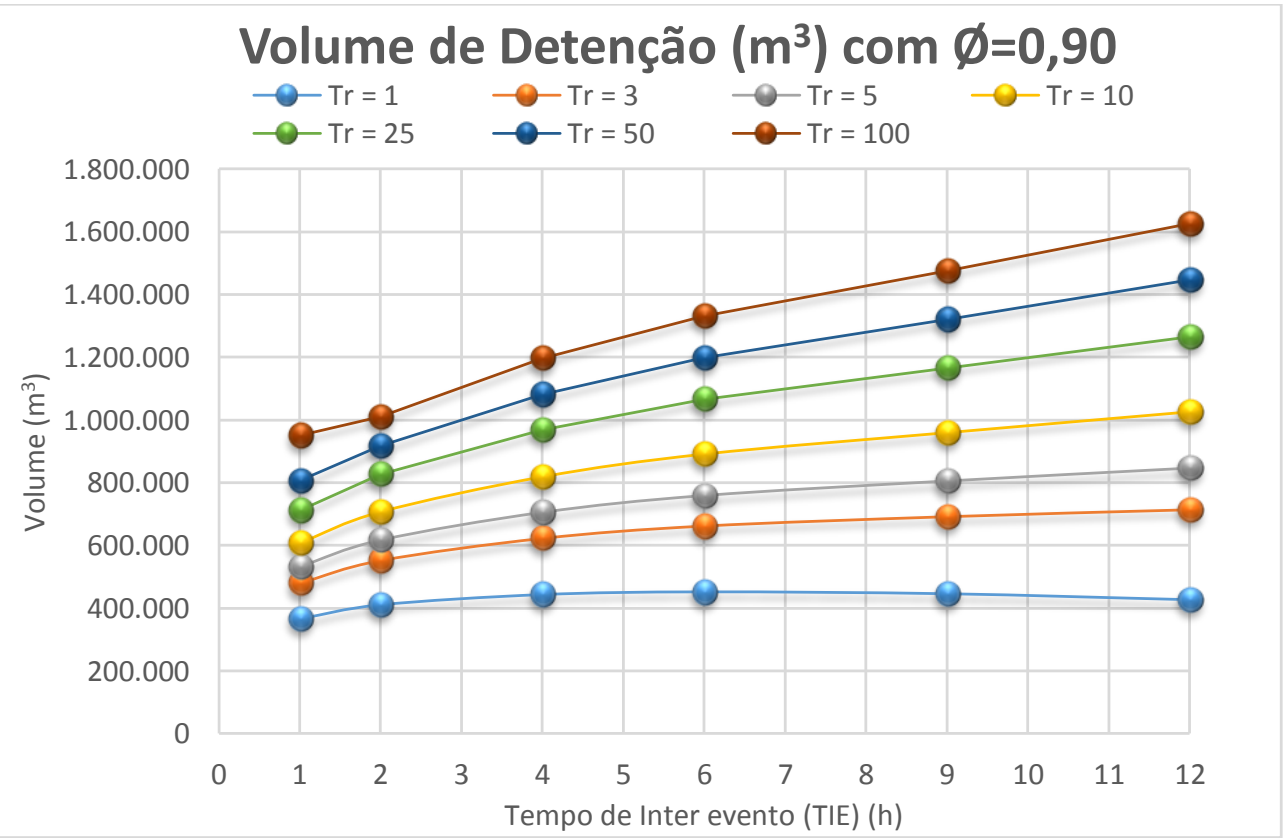

Figura 11 - Volume de Detenção do Reservatório $V a\left(\mathrm{~m}^{3}\right)$ com coeficiente de escoamento superficial $(\varnothing)=0,90$. 
O volume do reservatório de retenção é inferior ao necessário, o que corresponde a apenas $22,34 \%$ do volume necessário para um amortecimento significativo. Caso se considera a situação de maior adensamento populacional $(\varnothing)$ $=0,90, \quad \mathrm{o}$ volume necessário para o amortecimento, para um período de retorno de 1 ano, seria de $366.500 \mathrm{~m}^{3}$, desta forma, o volume do reservatório corresponderia somente a $16,4 \%$

do volume necessário.

Caso se desejasse o dimensionamento para um período de retorno mais adequado à macro drenagem, de no mínimo de 25 anos, o volume existente seria ainda menor, pois, para a situação $(\varnothing)=0,70$ corresponderia a apenas $11,41 \%$, e para $(\varnothing)=0,90$, de apenas $8,4 \%$.

\section{VANTAGENS DO MODELO ANALÍTICO PROBABILÍSTICO}

É um método simples uma vez que se baseia exclusivamente nas informações pluviográficas, desta forma não utiliza os vários coeficientes (de infiltração, de vazão e entre outros) que foram desenvolvidos para regiões geomorfológicas distintas da região de Campinas. É recomendado, como opção robusta de dimensionamento, para pequenas bacias, que não possuem dados de vazão, ou outras informações, porém possuem dados de chuvas. É um método que utiliza os dados, do próprio local a ser analisado e precisa de uma série histórica de dados pluviográficos não muito longa (no mínimo de cinco anos de observações).

É um método cujo ferramental matemático é simples, porém com forte embasamento matemático teórico em relação aos métodos tradicionais, geralmente empíricos.

A praticidade na aplicação do método permite a obtenção direta dos volumes de detenção quase que de forma imediata, o que auxilia na gestão das enchentes urbanas e em alertas em caso de perigo de inundações pela defesa civil.

A aplicação do método possibilitou avaliar a eficiência do reservatório (piscinão) existente, evidenciando o que se é notado no verão, que o volume é insuficiente, uma vez que provoca o alagamento das áreas adjacentes, várias vezes no verão, não cumprindo minimamente sua função, que é o de laminação das ondas de cheias. Os cálculos foram realizados com um valor alto de vazão a ser liberada, pois se fosse mais conservador os volumes seriam maiores aos determinados.

\section{CONCLUSÕES SOBRE O MODELO ANALÍTICO PROBABILÍSTICO}

O estudo realizado na cidade de Campinas, na bacia do Ribeirão Anhumas, permitiu estabelecer as seguintes conclusões sobre o Modelo Analítico Probabilístico: Por meio de uma única expressão matemática (Equação 9) foi possível obter o volume de detenção mostrando-se prático a sua utilização para o planejamento e/ou pré-dimensionamentos dos chamados "piscinões";

Excetuando-se a parte do tratamento dos dados de precipitação, que foi necessária a elaboração de um programa computacional para permitir o cálculo dos parâmetros utilizados para cada tempo de inter evento variado. Uma vez elaborado o programa, a rotina de aplicação do método torna-se bastante simples;

A obtenção dos dados necessários, mostrouse um pouco trabalhosa na medida em que foi necessário trabalhar com dados pluviográficos discretizados de 20 em 20 minutos. Porém, após a elaboração do programa para o tratamento dos dados pluviográficos, a obtenção dos resultados pelo método analítico probabilístico mostrou-se simples e rápido;

Por meio de todas estas apreciações concluise que o método pode ser utilizado para as fases preliminares de projeto, obtendo assim os valores de referência máxima de detenção a ser utilizado de forma rápida e extremamente simples, uma vez que pode ser aplicado a diferentes intervalos de tempo e períodos de retorno em que as precipitações podem sofrer variações.

Permite, de uma forma expedita, avaliar a eficiência dos reservatórios existentes, o que permite, ao planejador, rever as necessidades de ampliação de reservatórios existentes ou a construção de novos, mas com os volumes mínimos previamente determinados, para cada período de retorno considerado.

\section{DEDICATÓRIA}

Dedico esse artigo In memoriam de Lela Abbud Gregório (minha amada mãe), falecida no dia 28/03/2020 (M.A.Gregório). 


\section{REFERÊNCIAS}

ADAMS, B.J. \& PAPA, F. Urban Stormwater Management Planning with Analytical Probabilistic Models, USA, John Wiley \& Sons, Inc. 2000.

ADAMS, B.J.; FRASER, H.G.; HOWARD, C.D.D.; HAFANY, M.S. Meteorologic Data Analysis for Drainage System Design, Journal of Environmental Engineering, v. 112, n. 5, p. 827848, 1986.

BURGUENO, A.; CODINA, B.; REDAFIO, A.; LORENTE, J. Basic statistical characteristics of hourly rainfall amounts in Barcelona (Spain). Theoretical and applied climatology, $v$. 49, n. 3, p. 175-181, 1994.

DAEE. Estudo de Águas Subterrâneas - Região Administrativa 5 - Campinas. São Paulo, p. 111-145, 1981.

DUNKERLEY, D. Identifying individual rain events from Pluviograph records: A review with analysis of data from an Australian Dryland Site. Hydrological Processes: An International Journal, v. 22, n. 26, p. 5024-5036, 2008.

IBGE - INSTITUTO BRASILEIRO DE GEOGRAFIA E ESTATÍSTICA, 2016. ftp://ftp.gov.br/Estimativas_de_Populacao/Estimativas_2016/e stimativa_2016_TCU.pdf - Censo Demográfico, 2018.
PMC. Noticia: Cidade recebe maior volume de chuva, em curto período, dos últimos 12 anos. http://www.campinas.sp.gov.br/noticiasintegra.php?id=25970. (Acesso em 12 Julho 2018), 2015.

RESTRO-POSADA, P.J. \& EAGLESON, P.S. Identification of independent rainstorms. Journal of Hydrology, v. 55, p. 303319, 1982

TASSI, R.; TASSINARI, L.C.S.; PICCILLI, G.A.; PERSCH, C.G. Telhado verde: uma alternativa sustentável para a gestão das águas pluviais. Ambiente Construído, v. 14, n. 1, p. 139154, 2014.

TORRES, R.B.; ADAMI, S.F; COELHO, R.M. (Orgs.) Atlas socioambiental da bacia do ribeirão das Anhumas. Campinas, SP, Pontes Ed., 2014.

Submetido em 9 de junho de 2019 Aceito para publicação em 8 de maio de 2020 